\title{
Finding Information About Active Learning
}

\author{
Joseph O'Donnell
}

Published online: 16 October 2011

(C) Springer Science+Business Media, LLC 2011

I wanted to write a brief editorial to make all our readers aware of some "neat stuff" that I happen to tumble across every once in awhile. I've never met her, but I'm such a huge fan of Dr Deidre Bonnycastle, Clinical Teaching Development Coordinator at the University of Saskatchchewan in Saskatoon,Saskatchewan, Canada. She puts together the most useful tool sets for educators that I've ever seen.

If you look up the definition of teaching in a dictionary, most of the definitions are along the lines of "imparting one's knowledge," but we all know that teaching is really "helping people learn." And we also know that being active with the material and making it meaningful is probably the best way to help people learn.

I was trying to get the students in my problem-based learning group to help their peers learn and came across this very valuable site from the Saskatchewan websitehttp:// medicaleducation.wetpaint.com/page/Active+Engagement.
I shared it with the students and they are doing all kinds of active engagement techniques... and we're having fun learning. I'd suggest you visit this site-it will enlarge your repetoire as a teacher and is filled with well tested "low-hanging fruit" that will help teachers get rave reviews and most importantly, help students learn.

That's tip one. Tip two is to go to the DR-ED website where, in one of the many informative chats taking place, I came across the Bonnycastle site, but DR-ED is filled with gems.

To reply or post messages to this list, direct your messages to: dr-ed@list.msu.edu.To manage your subscription go to:http://omerad.msu.edu/dr-ed/instructions.php. To explore the DR-ED archives (filled with many pearls), go to http://list.msu.edu/archives/dr-ed.html. If you need help, send an e-mail to: dr-ed-request@list.msu.edu.

These are two tips worth your attention!
J. O’Donnell $(\bowtie)$

Dartmouth Medical School,

Hanover, NH, USA

e-mail: joseph.f.odonnell@dartmouth.edu 